\title{
Proposta Alternativa para Ensino de Química no Ensino Médio: Visita à Fábrica de Refrigerantes
}

\author{
An Alternative Proposal for the Teaching of Chemistry in High \\ School: A Technical Visit to a Soft Drink Factory
}

\author{
Suely Rodrigues Cabeleira Andrade'; Carla M. Balan Nóbile²; Eliana Aparecida \\ Silicz Bueno ${ }^{3}$; Flaveli Aparecida de Souza Almeida ${ }^{3}$
}

\section{Resumo}

\begin{abstract}
$\mathrm{O}$ atual ensino nas escolas está muito distante das necessidades requeridas para a formação do aluno como cidadão. A visita à fábrica de refrigerantes tem como objetivo despertar o interesse dos alunos pela exploração e compreensão de situações do cotidiano. Essa proposta permite não só propiciar uma boa aprendizagem bem como promover uma integração dos conteúdos teóricos com a vivência prática. Palavra-chave: Ensino Médio, Fábrica de Refrigerantes, Educação.
\end{abstract}

\begin{abstract}
The current teaching progress in schools is very distant from the needs required for the student's formation as a citizen. In order to get the student's interest in exploring and comprehending of everyday facts, a visit to a soft drink factory was carried out. This proposal allows not only a good learning process but also the integration of theoretical concepts and living experiences.

KEY WORDS: Soft drink factory, High School, Education
\end{abstract}

\section{Introdução}

Um dos grandes desafios no ensino de Química é buscar diferentes estratégias para que o aluno do Ensino Médio atinja as competências e habilidades necessárias para a sua formação de cidadão, num contexto social e tecnológico.

Segundo Santos (apud SANTOS; SCHNETZLER, 1997), "os objetivos, conteúdo e estratégias de ensino de química atual estão dissociados das necessi- dades requeridas para um curso voltado para a formação da cidadania".

Chassot (1995) propõe que devemos ensinar química para permitir que o cidadão possa interagir melhor com o mundo, preparando para a vida, para o trabalho e para o lazer.

A contextualização sugerida pelos novos Parâmetros Curriculares do Ensino Médio(PCN) é um referencial para direcionar a organização e o

\footnotetext{
${ }^{1}$ Mestre - Departamento de Química-CCE - UEL, E-mail: sandrade@uel.br

${ }^{2}$ Especialista - Colégio Estadual Marcelino Champagnat - Londrina

${ }^{3}$ Doutora-Departamento de Química-CCE-UEL.
} 
aprendizado no ensino de Química no Ensino Médio (MENEZES et al, 2001).

De acordo com Santos e Schnetzler (1997), os temas sociais desempenham papel fundamental no ensino de Química, e tem como objetivo básico formar o cidadão. Os conteúdos químicos propiciam a contextualização, desenvolvendo a capacidade de participação e tomada de decisão com os debates em sala de aula e pela problematização de situações em que o aluno tenha de propor soluções.

Os professores da rede pública, com o apoio da Secretaria da Educação do Paraná, têm procurado desenvolver em suas salas de aula, atividades para facilitar a aprendizagem de conteúdos diversos, assim como promover a interdisciplinaridade (BUENO, 1999).

Os conteúdos, sugeridos por Santos e Schnetzler (1997), deverão ser de caráter interdisciplinar, englobando conhecimentos fundamentais da Química; a natureza do conhecimento científico; a tecnologia; os aspectos sociais; a ética e a moral.

Uma das estratégias mais utilizadas pelos professores, dentro desta abordagem contextualizada e interdisciplinar, é o uso de temas motivadores. Estes, quando estão relacionados com o dia-a-dia dos alunos, permitem que eles tenham mais interesse em aprender Química, uma vez que compreendem que realmente ela está presente em suas vidas. Este procedimento metodológico leva em conta os interesses e os conhecimentos prévios dos alunos e permite que o processo de ensino seja desenvolvido de maneira que o aluno construa e reconstrua o conhecimento.

Considerando a necessidade de relacionar os conteúdos químicos a serem desenvolvidos no Ensino Médio com a vivência dos alunos, desenvolveu-se uma atividade: "A visita à fábrica de refrigerantes", como tema motivador, uma vez que o refrigerante faz parte do cotidiano destes alunos. Este tema considerado de caráter social permitiu desenvolver alguns conteúdos de uma forma mais contextualizada e ainda discutir a função da Química na sociedade em que vivemos.

\section{Materiais e métodos}

Esta experiência foi desenvolvida na disciplina de Química, junto aos alunos da segunda série do Ensino Médio de uma escola da rede pública da cidade de Londrina.

Para que a visita à fabrica de refrigerantes alcançasse os objetivos propostos, algumas atividades foram desenvolvidas: leitura e discussão de um texto organizador, debates, aulas expositivas, resolução de questionários, aulas práticas relacionadas com o laboratório de controle de qualidade da fábrica.

Foi elaborado um mapa conceitual (Figura 1), pois o mesmo constitui uma representação explícita de um conjunto de significados conceituais incluídos numa estrutura de proposições que uma pessoa possui, que permite ao professor e aluno, dialogar, trocar, compartilhar um determinado conhecimento, ou reconhecer a falta deste e assim percebe-se a necessidade de uma nova aprendizagem (NOVAK; GOWIN, 1996).

Como organizador prévio do trabalho, foi apresentado aos alunos um texto de abertura, que inicia o debate entre o que o aluno já sabe e o que precisa conhecer. Este texto foi extraído do jornal Folha de Londrina, do dia 20/01/1996: "Mito da fórmula mágica atrai milhares de visitantes todo ano". Em uma aula de cinqüenta minutos, os alunos se reuniram em grupos e fizeram leitura silenciosa. A seguir, o mesmo foi lido em voz alta pela professora e na discussão vários tópicos foram discutidos: marca, qualidade, sabores, concorrência, tipos de embalagens e preços.

Após a discussão, a professora apresentou slides diapositivos e fotografias referentes a fábrica de refrigerantes da Antárctica Irmãos Balan \& Cia Ltda., à qual iria ser visitada pelos alunos. Foram identificadas as várias seções: almoxarifado, xaroperia, lavadora, misturador, máquina enchedora, inspeção, datador, empacotadeira e laboratório de controle de qualidade, com o objetivo de esclarecimento sobre seu funcionamento. Novos questionamentos surgiram, entre eles: Quais são os 


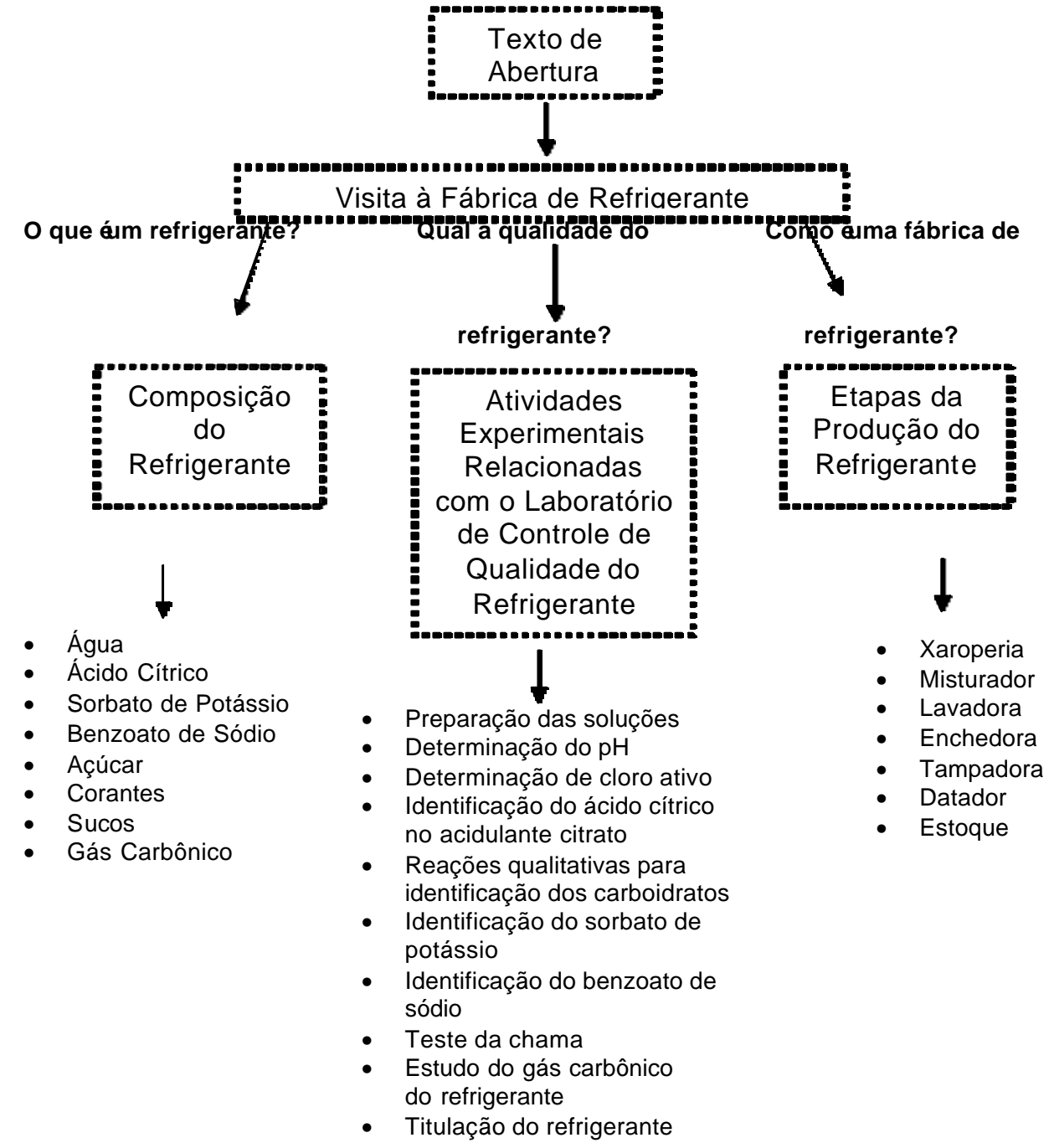

Figura 1. Estrutura do Mapa Conceitual

produtos químicos armazenados no almoxarifado? Por quê o refrigerante é embalado gelado? O xarope é segredo da marca do refrigerante? Durante a inspeção visual, já foram encontrados corpos estranhos nos refrigerantes? Qual o tempo de validade do refrigerante? As perguntas foram selecionadas, para que fossem respondidas durante a visita.

$\mathrm{Na}$ fábrica de refrigerantes, os alunos foram acompanhados pelo químico responsável, que explicou a composição, as etapas de produção do refrigerante $\mathrm{e}$ as atividades experimentais relacionadas com o laboratório de controle de qualidade. Nesta etapa, foram esclarecidas as dúvidas levantadas anteriormente pelos alunos.
Como roteiro de visita os alunos responderam um questionário (anexo 1) previamente elaborado com o objetivo de facilitar o acompanhamento e evitar a dispersão dos mesmos.

\section{Resultados e discussão}

Participaram desta atividade, quinze alunos do Colégio Estadual Marcelino Champagnat, da cidade de Londrina, PR. Verificou-se que os alunos apresentaram um grande interesse durante o desenvolvimento de todas as etapas, realizando registros, explorando os assuntos de forma objetiva, ativa e abrangente, antes, durante e depois da realização da visita. 
Os questionários foram respondidos no dia da visita por todos os alunos. A avaliação destes foi realizado pela professora, mostrando que os alunos puderam distinguir claramente as diversas fases de produção de refrigerantes, bem como as necessidades de um almoxarifado para armazenamento de produtos químicos, e de um laboratório de controle de qualidade.

Após a visita, foram selecionadas dez atividades experimentais, diretamente relacionadas com o controle de qualidade da fábrica. Essas atividades práticas foram selecionadas considerando os materiais disponíveis na escola, usando amostras de refrigerantes produzidos pela fábrica visitada e outros encontrados no comércio. Além deste aspecto, levouse em consideração as experiências que são rotina do laboratório de controle de qualidade da fábrica e que os alunos puderam presenciar durante a visita. Entre estas, salientam-se: preparação de soluções, determinação de $\mathrm{pH}$ (para comparação de acidez entre os diversos refrigerantes), identificação do ácido cítrico (este é encontrado no acidulante citrato utilizado no preparo de refrigerante), teste de chama (para identificação dos íons sódio e potássio encontrados nos conservantes usados no refrigerante), estudo do gás carbônico (tendo o refrigerante como amostra foi estudado a influência de temperatura e pressão). Dessa forma, os alunos puderam relacionar as situações observadas e/ou realizadas com a aprendizagem de química, promovendo integração dos estudos teóricos com as práticas de laboratórios executadas.

Os principais conceitos químicos discutidos quando se tratou da composição do refrigerante foram: estados físicos da matéria, densidade, substâncias puras e misturas, transformações química e físicas, ligações químicas, soluções, comportamento físicos dos gases, funções orgânicas, fórmulas estruturais dos compostos orgânicos, produto iônico da água, pH (COVRE, 2001; SILVA; NOBREGA; SILVA, 2001).
Esta atividade "Visita à fábrica de refrigerante" implica desvantagem se for utilizada apenas no sentido da curiosidade, da informação de mídia, ou mera situação descontextualizada da aplicação tecnológica, sem uma discussão crítica das implicações sociais e químicas.

\section{Conclusões}

A utilização do tema "refrigerantes" como um organizador para o ensino de alguns conceitos químicos para o Ensino Médio mostrou-se adequado por integrar as atividades extra-classe com a realidade dos alunos; proporcionou o conhecimento, por meio da descoberta e discussão, de alguns conceitos químicos relacionados com a composição e etapas do processo de produção dos refrigerantes. Desenvolveu o senso critico dos alunos, contribuindo para o crescimento intelectual e formação de cidadãos mais conscientes, pois eles puderam vivenciar as implicações sociais das aplicações da Química, como as medidas de segurança exigidas pelo trabalho do químico em uma indústria.

Pelo desenvolvimento do trabalho, ficou evidente que a contextualização sugerida pelos novos Parâmetros Curriculares do Ensino Médio é um referencial metodológico de ensino bastante eficaz para uma aprendizagem significativa.

Concluiu-se que a atividade proposta é uma estratégia à qual o professor deve recorrer com certa freqüência, visto que se realiza fora da sala de aula e portanto rompe com a monotonia do ambiente diário. A visita foi bem organizada e produziu um ensino integrado e permitiu atingir os objetivos propostos com motivação, clareza e eficiência. 
Proposta Alternativa para Ensino de Q uímica no Ensino M édio: Visita à Fábrica de Refrigerantes

\section{REFERÊNCIAS}

BUENO, E. A. S. Caderno de Resumos - Pró-Ciências 99. Londrina: Editora UEL, 1999

CHASSOT, A. I. Catalisando transformações na educação. Ijuí: UNIJUÍ, 1995.

COVRE, G. J. Química Total. São Paulo: FTD, 2001.
NOVAK, J. D.; GOWIN, B. Aprender a aprender. Lisboa: Plátano, 1996.

SANTOS, W. L. P. dos; SCHNETZLER, R. P. Educação em Química. Ijuí: UNIJUÍ, 1997.

SILVA, E.R. da; NOBREGA, O; SILVA, R. H. da. Química. São Paulo: Ática, 2001.

MENEZES, I. C. (Coord.) et al. Parâmetros Curriculares Nacionais (PCN): Ciências da Natureza, Matemática e suas Tecnologias. Brasília: MEC/SEMTEC, 2001. Parte 3.

\section{QUESTIONÁRIO}

Visita à Fábrica de Refrigerantes Antárctica Irmãos Balan \& Cia Ltda.

Nome: Data:

Objetivo: Relacionar os conceitos de química estudados no 2 ano do Ensino Médio com as atividades desenvolvidas na fábrica. Conhecer e identificar as etapas dos processos de produção de refrigerantes.

Atividades: Responder o questionário durante a visita.

1 - Que tipos de bebidas são produzidas nesta fábrica?

( ) Cerveja

( ) Refrigerantes

( ) Cerveja e refrigerantes

2 - Existe no almoxarifado da fábrica de refrigerantes produtos químicos?

( ) Não

( ) $\operatorname{Sim}$

3 - Qual o produto final obtido na xaroparia?

( ) Sucos

( ) Refrigerantes

( ) Xarope

4 - Qual a função do misturador?

( ) Misturar água e xarope

( ) Misturar gás carbônico, xarope e água

( ) Misturar o refrigerante pronto

5 - A validade de um refrigerante depende:

( ) Da embalagem

( ) da temperatura ambiente

( ) do gás carbônico 
6 - Qual a temperatura utilizada para realizar o processo de lavagem das embalagens?

( ) Entre 65 a $68^{\circ} \mathrm{C}$

( ) Entre 30 a $35^{\circ} \mathrm{C}$

( ) Temperatura ambiente

7 - Qual a função da água clorada após a lavagem das embalagens?

( ) Destruir microorganismo

( ) Dar sabor ao refrigerante

( ) Ajudar na coloração do refrigerante

8 - Qual a função da enchedora?

( ) Tampar o refrigerantes

( ) Colocar gás no refrigerante

( ) Colocar o refrigerante pronto na garrafas

9 - O laboratório na fábrica de refrigerante tem a função de:

( ) Preparar o refrigerante

( ) Controlar a qualidade

( ) Cuidar da higiene da fábrica

( ) Todas as alternativas

10 - Entres os tópicos da disciplina do segundo ano do ensino médio, listadas abaixo, quais você avalia ter aplicação na fábrica de refrigerantes:

( ) Ligações química

( ) Cinética química

( ) Ácidos

( ) Equilíbrio químico

( ) Soluções
11 - Gostou da visita
( ) $\operatorname{Sim}$
( )Não 